\title{
Effect of Technological Evolution on Usage Pattern: A Study on Mobile Internet Subscribers in Bangladesh
}

\author{
Rezwanul Huque Khan ${ }^{1 *} \quad$ Azfar Adib $^{2}$ Rabeya Sultana ${ }^{3}$ \\ 1.Assistant Professor, Institute of Business Administration, University of Dhaka \\ 2.Lead Engineer, Technology Division, Grameenphone Limited, Dhaka, Bangladesh \\ 3.Associate Professor, Management Information System, University of Dhaka
}

\begin{abstract}
As in most countries of the world, mobile internet has been playing a key role in the growth of internet subscriber-base in Bangladesh. While the country is at the verge of introducing advanced wireless internet connectivity via $4 \mathrm{G}$ technologies, this longitudinal study attempts to explore the effect (if any) of such technological evolution on subscribers' internet usage pattern. Data has been collected in two phases- first, just before the onset of $3 \mathrm{G}$ services (when $2 \mathrm{G}$ was fully dominant) and second, at the period when $4 \mathrm{G}$ launching was imminent (i.e., $3 \mathrm{G}$ is fully dominant), from the secondary sources of a leading internet service provider (as well as the top mobile operator) of the country and using a consumer survey of that mobile operator in both phases. A comparative analysis of the collected data shows that evolution of technology ( $2 \mathrm{G}$ to $3 \mathrm{G}$ ) has impact on certain consumption criteria while few of the patterns remain same even after the advancement. We identified few key issues (e.g., preference of devices, activities and website inclination, internet usage time, preferred area of service improvement etc.) that the mobile operators in Bangladesh should consider and show how those have practical and managerial implications for the maximum utilization of the future technological evolution (i.e., $4 \mathrm{G}$ deployment).
\end{abstract}

Keywords: mobile internet, usage pattern, subscribers, Bangladesh

\section{Introduction}

Internet now-a-days has become an integral part of our daily life through its unique power to connect people, to disseminate information and to facilitate execution of a diverse array of services conveniently and rapidly. Such a wide adoption of internet has been propelled by mobile internet (which in general indicates internet service provided through wireless mode) that offers mobility and ubiquity to the mobile phone users (Kim et al., 2007). GSMA Intelligence forecasts that there will be 9 billion total mobile subscribers globally by 2021 that would account more than the number of people with electricity at home $(5.3$ billion $)$ and predicts that there will be deployment of advanced technologies to provide faster connectivity (ITU/UNESCO Report, 2016). Mobile telecom operators have incorporated different generations of wireless internet services (e.g. 2G, 2.5G, 3G, 3.5G, 4G and WiMAX) with their traditional voice service (Tan and Li, 2009) so as to increase their customer base with value added services. Considering current scenario and future potentials, internet service has become a key portfolio for many telecom operators worldwide.

In Bangladesh, currently there are 128.281 million mobile phone users in total of six mobile operators (BTRC, 2017). Among them, the number of mobile internet subscribers is 63.12 whereas the total number of internet subscribers is 67.245 million. Similar to the global trend, the mobile internet service has been playing a pivotal role to the phenomenal growth of internet usage in Bangladesh. Mobile internet services are found to have great potential of business opportunities for mobile operators (Ashraf et al., 2014). The evolution of mobile technology aims toward higher bit rates and improved capacity that greatly reduce the cost of delivering data services. Mobile operators, therefore, can take the opportunity to exploit the multiservice synergies that arise from the new evolutionary technologies (Dulski and Persson, 2005). Consequently, wireless communication technologies were upgraded to $3 \mathrm{G}$ from $2 \mathrm{G}$ in October, 2012 allocating the $3 \mathrm{G}$ spectrum to the state-owned mobile operator and then allocated to other major operators in September, 2013. Despite various benefits of 3G services, the adoption rate of mobile internet subscriber did not increase as expected (Mahfuz and Latif, 2013; Christer et al., 2005) rather the subscription was argued to be declined for a year (Ashraf et al., 2014). At this backdrop, before $4 \mathrm{G}$ technology is launched, it deserves special attention to study the changes in consumption pattern of mobile internet users as $2 \mathrm{G}$ technology was upgraded to $3 \mathrm{G}$ technology. Again, while ITU/UNESCO Report (2016) state 4G deployments are proceeding apace, Gartner (2016) forecasts $3.7 \%$ decline of spending on mobile phones, tablets, printers and PCs. These paradoxes altogether highlights the significance of this study to explore the mobile internet subscribers' consumption pattern.

Consumption pattern are known to be influenced by different factors, like social factors (reference groups, family role and status) and personal factors (age, stage in the life cycle, occupation, economic circumstances, personality, self-concept, life style, values), as such it may vary between individuals and communities (Kotler and Keller, 2012). While mobile operators are developing mobile internet based services and also offering handheld devices with different packages, for them, it is imperative to know such consumption 
parameters of its subscribers for multifarious reasons, for instances-

a. Technological Perspective: For resource planning and, effective dimensioning and design of various components of data network (specially the core network components); it is quite essential to know the traffic characteristics (which is in fact derived from such consumption pattern) (Konstantinopoulou et al., 2000).

b. Marketing/Sales Perspective: For formulating appropriate product strategy, product positioning, marketing communications.

c. Strategic Perspective: To analyze and predict the holistic scenario while formulating appropriate strategy as an internet service provider, such insights can appear useful.

Given the context, in this study, we aim to find out the changes of subscribers' usage trend in terms of device preferences, popular content, popular web domain and choice of improvement criteria to offer insights to the mobile internet service providers and other stakeholders in Bangladesh.

\section{Literature Review}

Technology is constantly evolving and changing how people do things. With the increased use of technology in our day-to-day life, we are behaving in a way and operating in an ecosystem that has never been the case. Mobile internet service is currently one of the fastest-growing telecommunications technologies. Advanced wireless technologies provide people with "higher bandwidth, audio and video services, as well as mobile internet access all in one mobile environment" (Mardikyan et al., 2012). While 2G systems offered various basic features to the users, 3G mobile systems facilitated various attractive multimedia services (simultaneous transmission of audio, video and other data services) at a relatively higher speed (Patil et al., 2012). Similarly, deployment of 4G system is expected to further increase download speeds and uploads speeds significantly while web browsing would be much faster (0.78s to load a webpage, versus 1.06s) (ITU/UNESCO Report, 2016).

\subsection{Global Perspective}

NTT DoCoMo in Japan launched mobile internet service for the first time in 1999. They also pioneer in commercially run 3G network. Mobile internet is rapidly expanding to every part of the globe; strongly challenging the traditional fixed internet services. A breakthrough occurred in 2008, when mobile phones allow internet access along with personal computers. Now, majority of the internet subscribers use mobile phones than PC to access internet. According to StatCounter, world wide mobile internet usage surpasses desktop usage in 2016, accounting for $51.3 \%$ of visits from mobile devices compared to $48.7 \%$ from desktop. As shown in Fig. 1, mobile internet (also known as mobile broadband) has been going and also expected to go through an exponential growth in the upcoming years (Ericsson, 2013). Fig. 2 displays the content wise share of mobile internet traffic in 2013 (Ericsson, 2013). Asia pacific region is expected to dominate mobile internet use both in terms of absolute subscribers' number and of growth opportunity. The survey of GSMA intelligence (2015) reveals that more than $50 \%$ of global mobile internet subscribers expected to come from Asia Pacific by 2020.

Past research found link between mobile-based technology and users' behavioral pattern (McMillan, 2016). In a survey conducted by Accenture among mobile internet users of 13 countries of North America, South America, Europe and Africa; it was found that $69 \%$ of the respondents have used the service through a

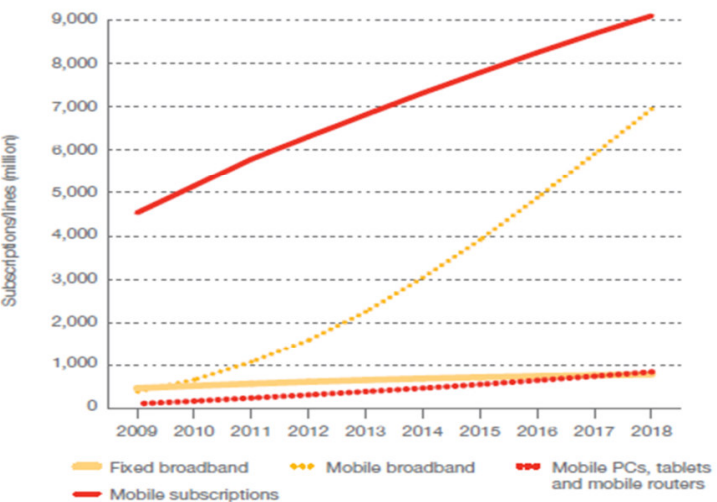

Figure 1: Fixed and mobile broadband subscriptionsglobal scenario

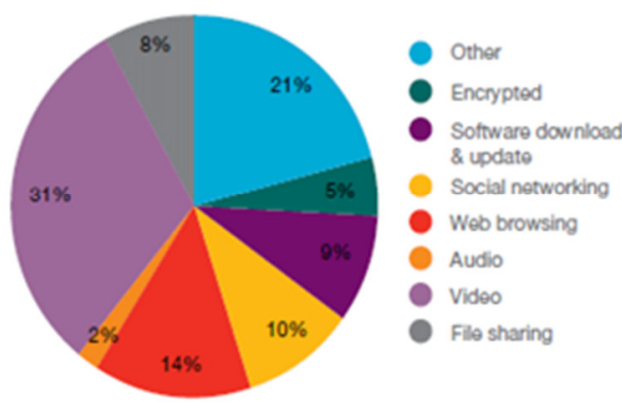

Figure 2: Content wise share of mobile internet traffic- global scenario

mobile device, $61 \%$ did so through a smartphone, $37 \%$ through a netbook and $22 \%$ through a tablet. Again, $62 \%$ use it for social networking, $58 \%$ have used the service for personal matters while $20 \%$ for work related matters (Accenture Consulting, 2012). Tshering (2013) surveyed 376 internet users in Bhutan and presents that majority of the people $(17.17 \%)$ use Internet to seek information, followed by email services 
(15.67\%) while most popular Internet sites are chat sites and social medias (11.13\% and 11.46\%).

In a study where distribution patterns of the subscriber's data access behavior were analyzed in terms of time and space, it was found that both duration and interval of subscribers' data access follow a normal distribution (Wu et al., 2013). Another study conducted on four hundred cell phone subscribers of Malaysia and Singapore) identified five needs based segments among the early adopters of mobile data service. The segments were: Mobile Professionals (using the service for professional purposes like: e-mail, calendaring); Sophisticates (using it as a status indicator); Socialites (using to maintain social communications); Technotoys (technologically savvy people) and Lifestyle (using it as an assisting service in various activities of daily life). Two additional segments were detected as unlikely to adopt the service: Misers (unwilling to pay for mobile data service) and Laggard (last to know about and adopt new technologies). The study also found that young subscribers with lower income and less education were using the service more for entertainment purposes than other purposes (Gilbert and Kendall, 2013). In a study on Greek market by Indrawati et al. (2010) found price as a determinant factor for $3 \mathrm{G}$ mobile services adoption.

Devices used by subscribers for mobile internet services are commonly divided into two broad categories by the mobile internet service providers- a) Large Screen Devices: Laptop/desktop connected through modem and b) Small Screen Devices: Various devices including featured phones, smart phones, tablets etc. While researching on user's behavioral changes with social innovation, Bresciania and Colorni (2016) found that portable devices have a role in influencing people's choices and consumption pattern. According to Nielsen report (2014) half of adult Australians access the internet via mobile devices (such as mobile phone, tablets) because of its portability, multitasking capability and touch screen interface. This number is predicted to increase worldwide as GSMA Intelligence and Ericsson forecast the mobile subscription will grow to 9 billion by 2021 , of which $85 \%$ will be using mobile internet and over two thirds will be using smartphones (as in ITU/UNESCO Report, 2016).

\subsection{Local Perspective}

Bangladesh, a country located in South Asia (adjacent to India \& Myanmar), having a population of 160 million in an area of $147,570 \mathrm{sq} \mathrm{km}$, is the eighth most populated country of the world. Internet was introduced in Bangladesh in the early 1990s, it became commercially available in the mid1990s followed by the launching of GPRS-EDGE based (2G) mobile internet service in 2005 and WCDMA based 3G internet service in the end of 2012. Despite its weak ICT infrastructure (Khan et al., 2015), currently number of internet subscribers in the country is about 67.245 million; almost $94 \%$ of them (63.12 million) are mobile internet users while just $6 \%$ (4.125 million) are fixed internet subscribers (BTRC, 2017).

There have been few studies undertaken concerning how and for what purpose individuals use the Internet in Bangladesh. In a study carried out in 2007 among the faculty members of a public university in Bangladesh, e-mail and web browsing were found as principal online activities for majority of the respondents (75\% and 65\% respectively) (Azam, 2007). In a survey (on 2009) focused on female internet users of Bangladeshi cities; it was observed that internet usage at home has been increasing very potentially among females; being accelerated by different factors like: need of internet from male member of the family, academic/professional work and also the desire of women to gain up-to-date knowledge (Choudhury, 2009). In another study among home-based internet users, it was found that majority of the respondents spend around an hour or less each day using internet. E-mail was their most preferred application and communication was perceived as the major benefit of using internet (Dwivedi et al., 2006). Again, in a study while 2G was dominant, Mostofa (2011) argued access speed as an important factor for Bangladeshi students and suggested for increase of bandwidth for faster connectivity.

After 3G has been introduced in the Bangladeshi market at the end of 2012, no comparative study regarding changes in consumption pattern of mobile internet subscribers is found. This study addresses this gap and offer insights for the mobile internet service providers and the others stakeholders while $4 \mathrm{G}$ technology is at the verge of deployment.

\section{Methodology}

This longitudinal study to explore the changes of usage pattern of mobile internet subscribers collects both primary and secondary data in two phases. In the first phase, data was collected from different reporting platforms of the country's leading mobile operator- Grameenphone during January-February, 2013 when 2G was fully dominant and launching of $3 \mathrm{G}$ technologies was imminent. At that time, to capture various attributes of internet usage, a questionnaire was sent to 100 mobile internet users via online of which eighty two (82) were received. This sample selection was judgmental and based on convenience, and consisted of students and service holders residing in Dhaka city (capital of Bangladesh) and who are regular users of internet services. Those users are using mobile internet services for more than five years. Data of same attributes was again collected from operator's network during January-February, 2017 and the same questionnaire was sent to the previous 100 
respondents (section 3.1 illustrates the respondents' profile) to know their recent usage pattern. The number of filled-in questionnaire in this phase was eighty six (86) of which seventy nine (79) responded earlier. To maintain the rigor and consistency, we selected those seventy nine (79) respondents who were common in both phases of the questionnaire survey. This second phase of data was collected when $3 \mathrm{G}$ was fully dominant and $4 \mathrm{G}$ technology is about to launch. In addition, data was collected from different websites, reports and journals to cross check and validate the data. Data collected thus in two phases (during the period of $2 \mathrm{G}$ and $3 \mathrm{G}$ ) allowed us to explore changes in subscribers' usage pattern as advanced technology (in our case 3G) was deployed. For analyzing the collected data from different sources, a quantitative method was adopted. We used Microsoft Excel for different analysis of the collected data.

\subsection{Survey Respondents' Profile}

In both scenario (2013 and 2017), demography of survey respondents remained similar since the sample selection was same. Majority of them were of aged in the range of 25-34 years being service holder while $46 \%$ of the respondents were students. The respondents were mostly male $(78 \%)$ and having higher academic qualifications (bachelors or masters). Figure 3 below shows the respondent profile.
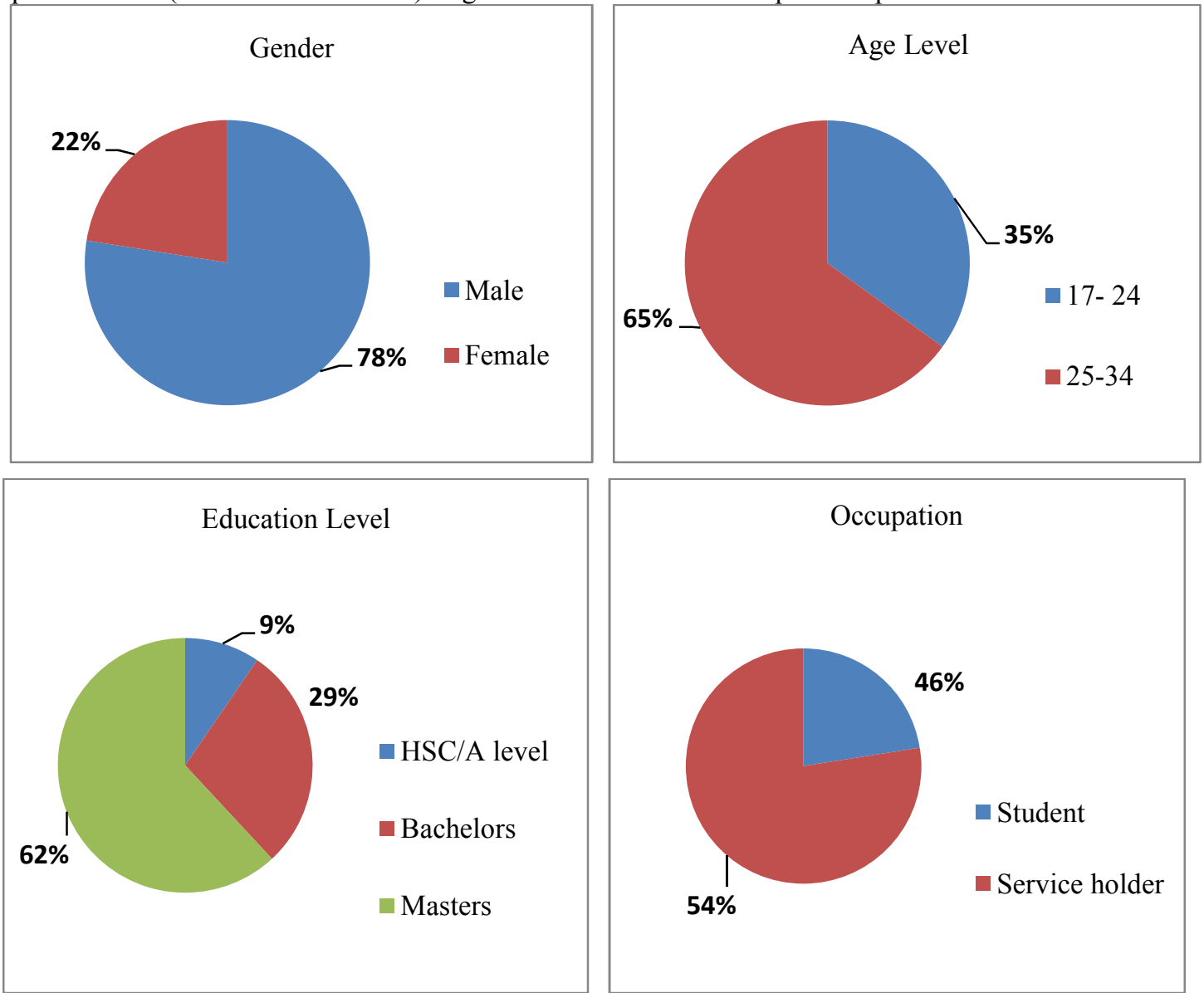

Figure 3: Demography of Survey Respondents

\section{Analysis and Findings}

\subsection{Preference of Devices for Mobile Internet Service}

Based on the mobile operators' network statistics our analysis shows that there has been a significant change of use of device for mobile internet services after $3 \mathrm{G}$ technologies have been introduced in the market. Figure 4 illustrates the change of usage from 2013 to 2017. It shows, in 2013, when only 2G services were available, large screen traffic (i.e., laptop or desktop with mobile modem) was dominant over small screen (i.e., handheld mobile phone) as $56 \%$ of data volume was consumed by large screens. On the other hand, we found that in 2017 data usage in small screen increased significantly, and $87 \%$ of overall data volume was consumed in small screen devices while it was only $44 \%$ earlier. This pattern is consistent with the findings from respondents' survey. 


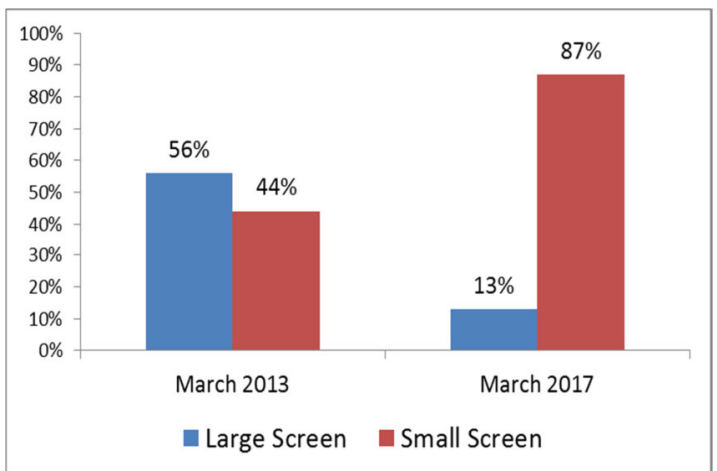

Figure 4: Use of Device for Mobile Internet Services (Network data)

Figure $5 \mathrm{a}$ and $5 \mathrm{~b}$ below illustrate that in $2013,60 \%$ of the respondents marked large screen devices as their mostly used device for mobile internet service, while in 2017 it was only $14 \%$. Our analysis also shows that as a small screen mobile device subscribers' preference of Android smartphone remains same but there has been a huge increase in its use from 19\% in March 2013 to 71\% in March 2017. In addition, iphone is also found to gain market share with advancement of wireless connectivity. These findings might be attributed to the fact that with the better speed of $3 \mathrm{G}$ technologies a good number and variety of small screen devices increased in the market by a large margin, along with the inclusion of huge number of web services and applications. Eventually, it attracted users to the smaller screen devices.

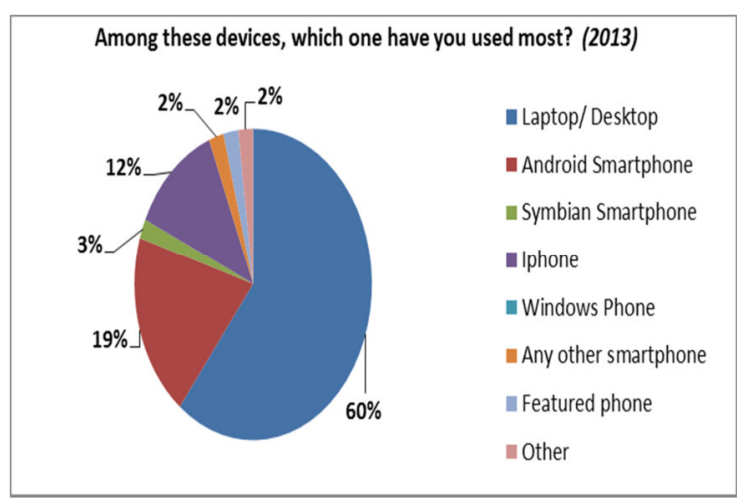

Figure 5a: Use of Device for Mobile Internet

Service during $2 \mathrm{G}$

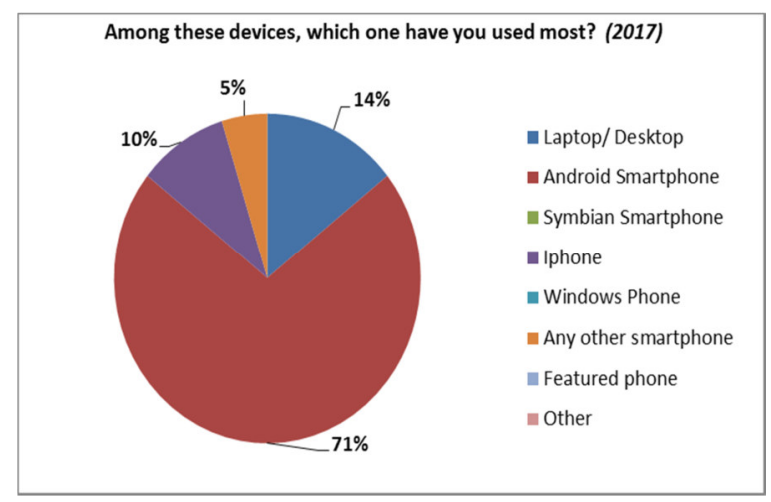

Figure 5b: Use of Device for Mobile Internet Service during $3 \mathrm{G}$

Further insights from network supports this trend as it shows (in Figure 6 below) that traffic proportion of smartphones has increased from $63 \%$ during $2 \mathrm{G}$ to $87 \%$ during $3 \mathrm{G}$. Among these smartphones, traffic generated from Android devices got a huge increment, $25 \%$ to $87 \%$ (in Figure 7) while traffic generated from Symbian devices has declined from $43 \%$ in 2013 to 1\% in 2017, almost a state of extinction. It indicates customers' increased preference of Android-based mobile devices for mobile internet services offered by operators after $3 \mathrm{G}$ was deployed.
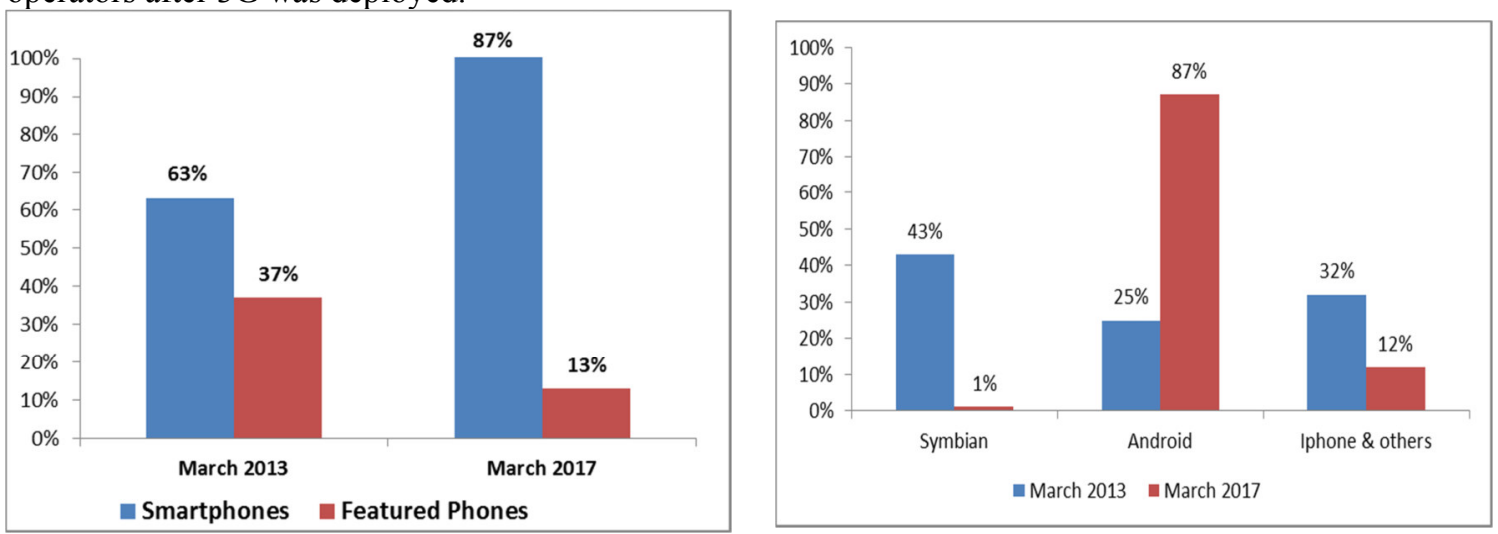

Figure 6: Comparison of traffic distribution between Figure 7: Comparison of OS-wise traffic distribution Smartphone and Featured Phone 


\subsection{Activity and Website Inclination Using Mobile Internet}

Our analysis shows that the customers' activities using mobile internet remained almost similar before or after the technological advancement (i.e., 3G deployment). In both cases, social networking was the activity at which respondents spent most of their times followed by web browsing. These two activities have been combinedly found to be the most popular activities to at least $80 \%$ of the respondents while video/text chatting was the activity at which lowest time was spent by the respondents.
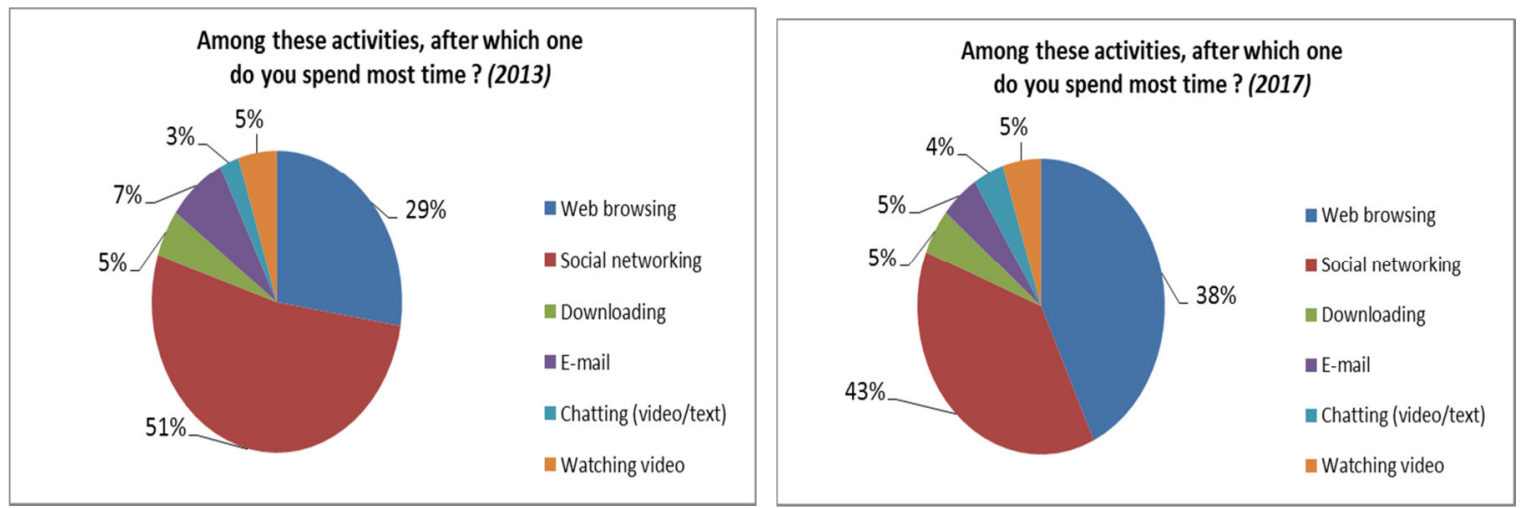

Figure 8a: Activity inclination during 2G (2013) Figure 8b: Activity inclination during 3G (2017)

Again, as indicated by the previous findings, in both cases, the website that respondents visited most was Facebook while Google was the second choice during 2013 which slipped marginally to third position in 2017. On the other hand, static chat, content and blogging sites (e.g., gpworld.com, mig33.com \& blogger.com) seem to get replaced by advanced app based services (Wowbox, instagram) and mobile TV services (digijadoo.net) when $3 \mathrm{G}$ was dominant. However, this is an expected trend with the increasing usage of smartphones. In 2017, increasing popularity of news sites is also noticeable in the ranking wherein among the top 10 sites two are news sites- "prothom-alo.com" and "kalerkantho.com". Youtube has also arrived in top 10, indicating increased consumption of video contents.

Table 1: Comparison of Websites Consuming Highest Data Volume (network data)

\begin{tabular}{lll}
\hline Rank & March 2013 & March 2017 \\
\hline 1 & facebook.com & facebook.com \\
2 & google.com & wowbox.com \\
3 & grameenphone.com & google.com \\
4 & yahoo.com & youtube.com \\
5 & dsebd.org & digijadoo.net \\
6 & mig33.com & kalerkantho.com \\
7 & blogger.com & instagram.com \\
8 & espncricinfo.com & grameenphone.com \\
9 & gpworld.com & espncricinfo.com \\
10 & google-analytics.com & prothom-alo.com \\
\hline
\end{tabular}

\subsection{Internet Usage Time}

Our data analysis shows that internet usage schedule do not change too much due to technological advancement rather it remained almost same having over $50 \%$ of survey respondents found to use internet most in between 6 PM to 12 AM both in 2013 and 2017. In addition, we found that the use of mobile internet from 6 AM to 12 PM and 12 PM to 6 PM increased to some extent, which reflects the increase of internet use by students and the service holders when they are mobile or at their affiliated office or institution. However, the usage during other two schedules declined marginally even though time from 6 PM to 12 PM was at the most popular time to use internet. 
At what period of the day, do you usually use mobile internet most? (2013)

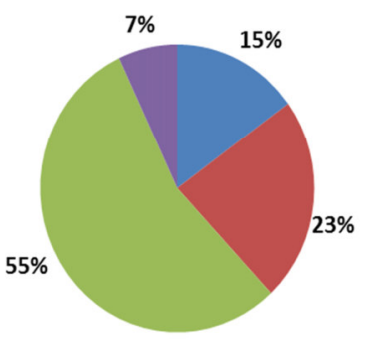

चrom 6 AM to $12 \mathrm{PM}$

From $12 \mathrm{PM}$ to $6 \mathrm{PM}$

From 6 PM to $12 \mathrm{AM}$

- From $12 \mathrm{AM}$ to $6 \mathrm{AM}$
Figure 9a: Preferred Time of Internet Use in 2013

\subsection{Preferred Area of Service Improvement}

On which side of mobile internet service,would you like to see some improvement?

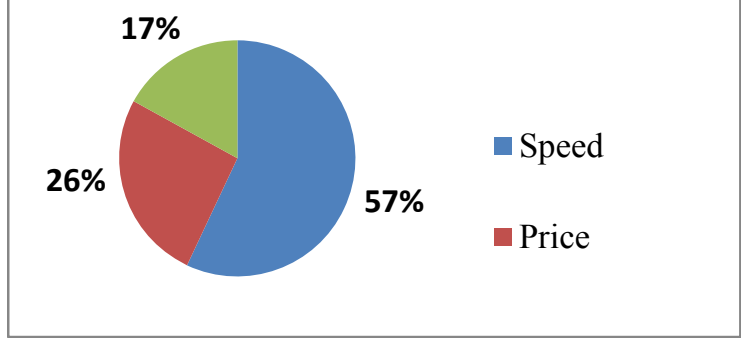

Figure 10a: Preferred Area of Service Improvement

while $2 \mathrm{G}$ is dominant

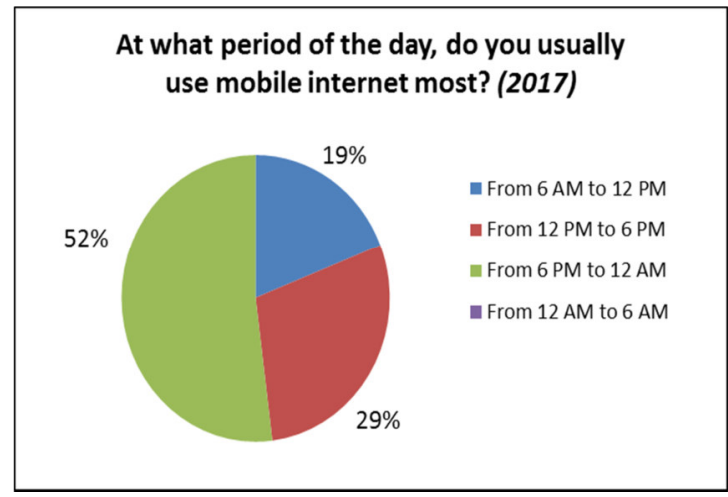

Figure 9b:Preferred Time of Internet Use in 2017

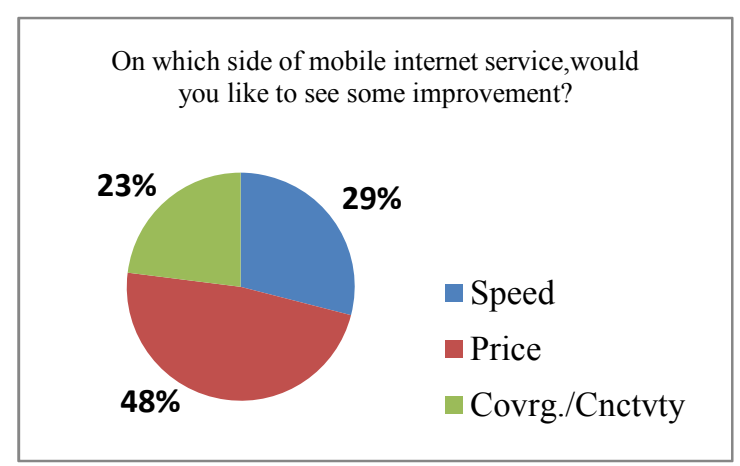

Figure 10b: Preferred Area of Service Improvement

while $3 \mathrm{G}$ is dominant

The figure above shows that during the period when $2 \mathrm{G}$ was dominant, speed was the major concern for the mobile internet subscribers followed by price. We found $57 \%$ of respondents mentioned speed needs to be improved while $26 \%$ suggested decrease of price. It also needs to be mentioned that internet coverage or constant connectivity was also a reasonable issue then for the users. On the contrary, situation seems to be quite different when $3 \mathrm{G}$ technologies are dominant. Our analysis shows that $29 \%$ of the respondents mentioned speed to be improved whereas $48 \%$ suggested for price decrease. In addition, subscribers' concern for coverage or constant connectivity has also increased from $17 \%$ to $23 \%$ even after the evolution of technology.

\section{Discussions}

By conducting the analysis of longitudinal data, our study shows how mobile internet subscribers' usage pattern changes with the evolution of advanced telecommunication technology- from $2 \mathrm{G}$ to $3 \mathrm{G}$ technology in Bangladesh. In 2013, just before the launching of $3 \mathrm{G}$ service, the subscribers were mostly relying on large screen devices for internet use, and speed was their major concern. As $3 \mathrm{G}$ provides faster connectivity, arrival of $3 \mathrm{G}$ technology opened up a new horizon for the users. Enhanced speed of $3 \mathrm{G}$ removed the speed concern, but price became the major concern for users due to high volume of data usage. This development along with rapid increase in smartphone supply (coupled with its declining price) caused exponential increase in smartphone usage (particularly Android based smartphones which are vastly available in different popular categories in local market). As a consequence, popularity of advanced app-based services became high and few related websites were ranked into the top list. However, subscribers' inclination to visit Facebook remained at the top of the rank in both cases. Social networking and browsing as most preferred activity remained unchanged. The timing of internet use also appeared to have marginal change. As such, while mobile internet service in Bangladesh is on the verge of another technical transition ( $4 \mathrm{G}$ deployment), it can be expected that $4 \mathrm{G}$ services (which will provide several times higher speed than $3 \mathrm{G}$ ) will have similar effect on mobile internet usage. Accordingly, our study suggests few issues into consideration for the managers and policy makers-

$>$ As the speed is expected to increase sharply, attention should be paid to develop advanced app-based services and real-time or stored video steaming facilities to cope with the users' expectation.

$>$ With speed the volume of data usage may increase, so price should be reasonable to attract more users and for more consumption to achieve economies of scale. 
$>$ With increase of number of internet users, the uninterrupted service (constant connectivity) has been found as one of the concerns for users. Appropriate strategies need to be taken by internet provider to address this issue.

$>$ With the arrival of $4 \mathrm{G}$ along with new dimension of services, small screen usage is expected to increase further. It indicates that focus should be given to the design and development of websites, contents and services as such those are well supported by mobile devices.

$>$ Partnering with device manufacturers can help craft strategy to capitalize the users' preference of Android based smartphones and small screen device as users are expected to grow in number in the developing countries (ITU/UNESCO Report, 2016).

$>$ Having wealth of data on user behavior; usage pattern; ranking of website visits, mobile operators can offer insights for marketers to formulate online promotion and campaign strategies.

$>$ Time preference of using internet at the same time may cause traffic congestion and customer dissatisfaction, so by adopting appropriate traffic management strategies mobile internet service providers can avoid risk of possible connection lose and can reduce customers' churn rate.

$>$ As mobile market is very turbulent and competition is fierce, operators can sustain and strengthen their positions as well as drive growth by continuing technological advancement to provide better service along with extensive device offering and optimized price.

\section{Conclusion}

Our study explores few of the preferences of mobile internet subscribers that changes as advanced technology is deployed, while very few parameters remain same. Despite the fact that some of the parameters of mobile internet subscribers' usage remained almost similar, technological advancement (with the availability of appropriate device) changed the overall scenario significantly. We identified few critical issues and offered some suggestions based on our findings so that $4 \mathrm{G}$ technologies can provide expected acceleration for mobile internet services in the country. One of the limitations of this study is its low sample size which represents only the capital of the country. The scenario in other cities or sub-urban area might be different which needs further investigation. Future studies can also explore the effects of demographic factors on the mobile internet subscribers' usage pattern.

\section{References}

Accenture Consulting. (2012), Mobile Internet- Spawning New Growth Opportunities in the Convergence Era, retrieved on 24 February, 2017, retrieved from https:/www.accenture.com/gb-en/insight-mobile-web-

watch-2012-mobile-internet.

Ashraf, M. M., Mia, M. A. H. \& Hasan, N. (2014), Factors Affecting Mobile Internet Usages in Bangladesh, Bangladesh Journal of MIS, Volume 6, No 2, pp. 17-35.

Azam, M. S. (2007), Internet Adoption and Usage in Bangladesh, Japanese Journal of Administrative Science , 43-54.

Bresciani, C., Colorni, A., Lia, F, Luè, A., \& Nocerino, R. (2016), Behavioral change and social innovation through reward: an integrated engagement system for personal mobility, urban logistics and housing efficiency, Transportation Research Procedia 14, 353 - 361 .

BTRC (Bangladesh Telecommunications Regulatory Commission) (2017), Internet Subscribers in Bangladesh. Retrieved from http://www.btrc.gov.bd/ retrieved on 25 February, 2017.

Choudhury, N. (2009), How are women fostering home Internet adoption? A Study of Home Based Female Interent Users in Bangladesh, Triple Cognition,Communication,Co-operation.

Christer, C., Kaarina, H., Petteri R. \& Pirkko, W. (2005), Adoption of Mobile Services across Different Technologies, 18th Bled e Conference e Integration in Action, Bled, Slovenia, June 6 - 8, 2005.

Dulski, A. \& Persson, M. (2005), Mobile broadband-Operator opportunities, Ericsson Review, Retrieved on 15 February, 2017, Retrieved from https://www.ericsson.com/ericsson/corpinfo/publications/review/2005.../2005016.pdf

Dwivedi, Y., Khan, N.\& Papazafeiropoulou, A. (2006), Consumer Adoption and Usage of Broadband in Bangladesh, Americas Conference on Information Systems.

Ericsson. (2013), Ericsson Mobility Report: On The Pulse Of The Networked Society, retrieved on 23 February, 2017, retrieved from https://www.ericsson.com/res/docs/2013/ericsson-mobility-report-february2013.pdf

Gartner (2016), The era of double-digit smartphone growth is over", accessed on 1 March 2017, retrieved from www.digitaltrends.com/mobile/gartner-slowing-smartphone- growth/

Gilbert, A. L. \& Kendall, J. D. (2013), A marketing model for mobile wireless services", in 36th Annual Hawaii International Conference.

GSMA Intelligence. (2015), Mobile internet usage challenges in Asia - awareness, literacy and local content. 
retrieved

on

\section{3}

February

2017 ,

retrieved

from

Heisler, Y. (2016), Mobile internet usage surpasses desktop usage for the first time in history. Retrieved on 13 February, 2017, retrieved from http://bgr.com/2016/11/02/internet-usage-desktop-vs-mobile.

Indrawati, Murugesan, S. and Raman, M. A. (2010), New Conceptual Model of Mobile Multimedia Services (MMS) and 3G Network Adoption in Indonesia, International Journal of Information Science and Management, Special Issue, January / June.

ITU/UNESCO Report. (2016), The state of broadband 2016: broadband catalyzing sustainable Development, September, retrieved on February 2017, retrieved from http://broadbandcommission.org/Documents/reports/bb-annualreport2016.pdf

Khan, R. H., Joe, N. \& Constantinides, P. (2015), ICT Driven Transformation of State-Owned Enterprise in a Developing Country, Twenty-Third European Conference on Information Systems (ECIS), Münster, Germany.

Kotler, P. T. \& Keller, K. L. (2012), Marketing Management, 14th Edition, Upper Saddle. River, New Jersey: Prentice Hall.

Konstantinopoulou, C.N., Koutsopoulos, K. A., Lyberopoulos, G. L., \& Theologou, M.E. (2000), Core

Network Planning, Optimization and Forecasting in GSM/GPRS Networks, Symposium on Communications and Vehicular Technology.

Mahfuz, T. \& Latif, S. (2013), An Assessment of 3G Mobile Service Acceptance in Bangladesh, International Journal of Advanced Computer Science and Applications, Vol. 4, No. 11.

Mardikyan, S., Beşiroğlu, B., \& Uzmaya, G . (2012), Behavioral Intention towards the Use of 3G Technology, Communications of the IBIMA, vol. 2012. DOI: 10.5171/2012.622123

McMillan, K. A., Kirk, A., Hewitt, A \& MacRury, S. (2017), A Systematic and Integrated Review of MobileBased Technology to Promote Active Lifestyles in People with Type 2 Diabetes, Journal of Diabetes Science Technology, March, 11(2):299-307.

Nielsen Australian multi-screen report Q1. (2014), Retrieved on February 20, 2017, retrieved from http://www.nielsen.com/content/dam/nielsenglobal/au/docs/reports/australian-multi-screen-reportq32014.pdf

Patil, C.S., Karhe, R. R. \& Aher, M. A. (2012), Development of mobile technology: a survey, International Journal of Advanced Research in Electrical, Electronics and Instrumentation Engineering, 1(5), pp. 374-379.

Smith, A. (2015), Mobile Mania! Australians Spend on Average More Than an hour a Day on Their Smartphone, retrieved on 15 February, 2017, retrieved from http://www.nielsen.com/au/en/insights/news/2015/

Tshering, K. (2013), To Study the Internet Access and Usage Behavior in the Kingdom of Bhutan, International Journal of Computer Science and Electronics Engineering (IJCSEE), Volume 1, Issue 2, 2320-4028.

Tan, W. K. \& Li, H. Y. (2009), Mobile Service: An Empirical Study of the Behavior of 2/2.5G and 3G

Subscribers and Implications to Roll-out of WiMAX Network, International Conference on Management and Service Science (MASS 2009), September.

Wu, L. Y., Zhou, L. C., Jiang, H. \& Qian, X. (2013), Statistic Analysis of data access behavior in the mobile internet, in International Conference on Communications in China.

\section{Biographies}

Rezwanul Huque Khan is a doctoral researcher in Information Systems Management at Warwick Business School, University of Warwick, UK. He is an Assistant Professor of Institute of Business Administration, University of Dhaka, Bangladesh. His primary research interest focuses on e-commerce, ICT4D and digital service innovation, and he has several publications in leading national and international journals in the field of business studies.

Azfar Adib is currently working in Grameenphone Ltd. as Lead Engineer in Technology Division. He obtained his MBA (with major in Marketing) from IBA, University of Dhaka and B.Sc. in Electrical and Electronic Engineering Degree from BUET. He has been closely involved with various key endeavors of Grameenphone's Mobile Broadband Network since he started his professional career in Grameenphone as a member of Data Core Planning team.

Dr. Rabeya Sultana, PhD is an Associate Professor in the Department of MIS in University of Dhaka, Bangladesh. She earned her Ph.D in information systems from School of Business, Yonsei University, Korea and MS in Strategic IT management from Stockholm University, Sweden. Her primary research interests are in the field of Electronic Government, ICT for Development, IT management, Electronic Commerce, Social Media. 